\title{
The Impact of Game-Specific Factors on Brand Recall and Brand Attitude
}

\author{
Devika Vashisht \\ Assistant Professor, Department of Marketing, ICFAI Business School, India \\ dev2007.d@gmail.com
}

\begin{abstract}
Purpose: This experimental study provides empirical evidence of the effect of brand prominence in advergames on gamers' brand recall and brand attitude under varied game-involvement conditions from attention and elaboration perspectives.
\end{abstract}

Design/methodology/approach: A 2 (brand prominence: prominent or subtle) x 2 (gameinvolvement: high or low) between-subject measures design is used. 229 student gamers participated in the study. A between-subject measures MANOVA is used to test the hypotheses.

Findings: The results reveal that for an advergame with prominent brand placement, low gameinvolvement results in greater brand recall than high game-involvement. However, for an advergame with prominent brand placement, high game-involvement results in more favorable brand attitude than low game-involvement.

Discussion: These experimental findings suggest to marketers and game designers to cogitate for a right mix of game-specific factors while creating effective advergames to have stoutest positive advergaming effect on players' brand recall and brand attitude.

Keywords: Advergames, Brand prominence, Game-involvement, Brand placements

\section{Introduction}

Marketers always look for innovative ways to effectually promote their brands. With the progress of emergent promoting strategy known as branded entertainment, now advertising sites such as advergames have delivered advertising practitioners a new way to influence their customers' minds. In advertising literature, an advergame is labelled as a new marketing style that uses "branded products or images within an interactive video game and offers a unique hybrid of brand messaging" (Cicchirillo \& Lin, 2011: 1). It is also described as an interactive online game designed to promote a brand(s) from a specific advertiser (Vashisht and Mohan, 2018). Advertising literature shows that advergames are highly mesmeric in nature, highly interactive, easy modifiable, cost-effective, provide infinite entertainment, have viral marketing ability (Chen, Shen, \& Ma, 2012) and enhance the commercial time (Ipe, 2008) as compared to traditional advertising tools. Thus, these physiognomies of advergames show that, conceptually, advergames are very different from traditional advertising formats (Vashisht, 2015). Since, advergames are conceptually different from traditional advertising channels; it is likely the 
advergames vary in the extents of cognitive resources that are needed to play.

With the increase in the popularity that the advergames has aroused, the advertising finances have started to move away from traditional advertising formats to more advance and nontraditional advertising channels to effectively endorse their brands (Lee, Choi, Quilliam, \& Cole, 2009; Livemint, 2015). These large investments have begun to pay off. A report by eMarketer (2015) shows that in the year 2014 the worldwide digital advertising expenditure increased to US $\$ 145$ billion and would further increase to US $\$ 171$ billion in the year 2015. According to Dentsu Aegis Network News Report (2015), Carat - the leading global media network has predicted that digital advertising expenditure would be more than $25 \%$ of total advertising expenditure in the year 2016, driven by a rise in online advertising expenditure in the year 2015. Likewise, a report by Statista (2015) shows that India's digital ad-spending increased to US $\$ 0.45$ billion in the year 2012 and would reach US $\$ 0.97$ billion in the year 2015 and US $\$ 1.78$ billion by the year 2018 . Along with great earning potential, advergames have increased the ad-exposure time as well (Vashisht, 2015). It is found that the time spent by a consumer on an advergame is from 7-30 minutes per day which is higher as compared to an advertisement shown in television (Ipe, 2008). According to Business Wire (2008) report, advergames have boomed the market because of their ability to charm the young consumers who increasingly choose online and interactive media over traditional media tools when looking for amusement channels. Hence, specific focus on examining the advergaming effects on these young consumers is essential due to the population of young and tech-savvy adults that remain demographic which promoters and marketers incessantly strive to reach.

As the advertising finances are now being reorganized to embrace online gaming channels, it trails that online advertising has turned out to be one of the fastest emergent areas of research (Faber, Lee, \& Nan, 2004). In fact, a lot of research on advergames has been conducted in the past few years, however, most of these studies are content analyses (see Alvy \& Calvert, 2008; Dias and Agante, 2011; Folkvord, 2012; Folkvord, Anschutz, Wiers, \& Buijzen, 2015; Ghirvu, 2013; Hofmeister-Tóth \& Nagy, 2011; Moore, 2006; Nairn \& Hang, 2012; Paek, Quillium, Kim, Weatherspoon, Rifon, \& Lee, 2014; Youn \& Lee, 2012) and a few are experimental studies (see Cauberghe \& De Pelsmacker, 2010; Haung \& Yang, 2012; Lee \& Faber, 2007; van Reijmersdal, Rozendaal, E., \& Buijzen 2012). Still, in terms of what is known in the area of advergames, there remains a research gap of examining the advergaming effects of game specific features such as brand prominence and individual trait factors such as game-involvement on desired advertising outcomes. The recent studies addressing the effect of advergames on gamers' memory shows that due to the variation in positioning the brands in the games and advergames' high-involving nature, gamers' recall rates do get affected (e.g., Cauberghe and De Pelsmacker, 2010; Haung \& Yang, 2012; Lee \& Faber, 2007). Thus, in this context it is deduced that an understanding about the possible effects of brand prominence (location of brand placements in advergames prominent/central or subtle/peripheral) and gamers' game-involvement is very important in order to capture the impact of advergames on consumers' brand recall. Although extant literature has acknowledged the importance of the above mentioned advergame-factors - i.e., brand prominence and game-involvement as important attention and elaboration elements required understanding the advertising effects on consumers' brand outcomes; still studies considering them are very scant in the context of an emerging economy. As evident from the previous literature that consumer's attention capacity left to process in-game brand placements gets affected by and is conditional upon elaboration components (e.g., Krugman, 1983; McClung, Park, \& Sauer, 1985), it becomes very important to understand these three aspects from a theoretical as well as a practical point of view. Therefore, it would be interesting and beneficial for scholars, advertisers and policy makers to know and understand the roles of all these two 
factors - i.e., brand prominence (prominently placed brand or subtly placed brand) and gameinvolvement (high or low) in determining the persuasion effects from attention and elaboration perspectives.

Hence, considering this research gap, this paper seeks to establish whether there is a difference in brand recall and attitude towards brand embedded in the game because of the differences in brand prominence and game-involvement. We address this question through an experimental study highlighting the interaction effect of brand prominence and game- involvement on gamers' brand recall by taking the insights from Limited-Capacity Model of Attention (LCM: Kahneman, 1973; Lang, 2000) and Elaboration Likelihood Model (ELM: Petty \& Cacioppo, 1986). The study uses these two theoretic viewpoints as LCM describes how cognitive resources are apportioned when individuals process the brand- as well as the game-content while playing an advergame and ELM expounds when and how these cognitive resources get utilized for cognitive elaboration.

The remainder of this study is organized as follows. In the next section, theoretical development and hypotheses development are provided. Then we describe the research methodology followed by the results of hypothesis testing. Later, we present a discussion on results followed by the implications of our study findings. Finally, we conclude with limitations and directions for future research.

\section{Literature Review and Hypotheses Development}

\section{Brand Prominence and Game-Involvement}

In advertising literature brand prominence is defined as "the extent to which the appearance of the brand possesses characteristics designed to make it the central focus of audience attention" (Gupta \& Lord, 1998: 48). The brand placement is called as a prominent placement when "the product or other brand identifier is made highly visible by virtue of size and/or position on the screen or its centrality to the action in the scene" (Gupta \& Lord, 1998: 49). A brand placement is called as a subtle brand placement "when it is peripherally placed on game screen or in the background or when the brand size is very small" (Gupta \& Lord, 1998: 49). Extant literature on advergames reveals that prominent brand placements result in high brand recall because in a prominent placement the displayed brand name size at central position of the game screen is big enough to catch gamers' attention. As a result of high noticeability of prominent brand placements, brands are more likely to be retrieved from brand memory than subtle brand placements (e.g., Cauberghe \& De Pelsmacker, 2010; van Reijmersdal, 2009; Yang \& Roskos-Ewoldsen, 2007), though it is not the same story in all situations. As evident from the previous program-involvement studies that when it is a high involvement of a customer or viewer with a program/game, the activity of watching the program or playing the game becomes the primary focus for the viewer/gamer and attention on ad reduces because the attentional capacity required to process in-game brand placement becomes less (Krugman, 1983; McClung et al., 1985). Thus, gamers' program involvement is conceptualized as a boundary condition in the current paper as it is abstracted as a motivational aspect of viewers' involvement in past literature (Tavassoli, Shultz, \& Fitzsimons, 1995). Viewers' program involvement is described as a motivational state and a state of arousal or interest towards a program or an event that is induced by particular motives (Rothschild, 1984). In the recent literature, players' game involvement is also demarcated as the active interest in, engagement with and commitment to a game or an event (Laverie \& Arnett, 2000).

LCM (Kahneman, 1973; Lynch \& Srull, 1982) is employed in the present study to expound the impact of game involvement on players' brand memory and attitudes. It is based on an assumption that at a particular point of time one's attentional capacity is limited; henceforth if 
one does more number of tasks at a time, his/her total perceptual capacity gets fragmented into two portions: one gets used to perform the main activity and the rest gets used up for the secondary activity. According to Grigorovici \& Constantin (2004), in the context of advergames, for players, game-playing is the main activity and comprehending in-game advertising is the secondary activity. Consequently, when it is a case of high-involvement with the game, more perceptual resources get used in the game-playing activity (main activity) and less perceptual capacity relics to comprehend in-game brand placements. However, in case of low gameinvolvement, less perceptual capacity gets used in the game-playing activity and more perceptual capacity (spare capacity) remains to comprehend in-game advertising messages (Krugman, 1983; McClung et al., 1985). Consequently, low game-involvement leads to higher brand recall than high game-involvement situation (Krugman, 1983; McClung et al., 1985).

Based on the above mentioned rationales and insights drawn from LCM and Grigorovici \& Constantin (2004) work, it is anticipated that for an individual playing an advergame with prominent brand placement, the low game-involvement condition will result in higher brand recall than high game involvement condition. This possibility is based on a rationale that very less perceptual capacity will be used to process prominent brand placement (centrally placed brands) as the brand is highly noticeable and the gamer doesn't have to search much where exactly the brand while processing in-game advertising. Thus, a gamer playing a prominent placement advergame under a low game-involvement condition will use less of his/her perceptual resources for game-playing activity and hence will remain with more attentional capacity for in-game brand placements processing. As a result this condition will result in high brand recall. Also, since the player's game-involvement is less and has more spare capacity, he/she will elaborate more to find out the reasons behind placing a brand prominently in the game which will become the base for him/her to evaluate the embedded brand and form an attitude towards it. Consequently, an advergame with prominent brand placement under low game-involvement condition will result in less favorable brand attitude.

On the other hand, when game-involvement is high, more attentional capacity for gaming activity will be used and less spare capacity will remain which may not be high enough to process in-game placements. As a result, this situation will result in less brand recall but more favorable brand attitude as the gamer's capacity to analyze and process in-game advertising will be very less to capture and identify the reasons behind placing the brands in a game. Thus, based on these rationales, following hypotheses are offered:

H1. An advergame with prominent brand placement under low game-involvement condition will result in higher brand recall than high game-involvement condition.

H2. An advergame with prominent brand placement under high game-involvement condition will result in more favorable brand attitude than low game-involvement condition.

\section{Research Methodology}

\section{Development of Stimulus Materials}

We performed two pretests to select stimulus materials for the final experiment. The objective of conducting pretest 1 was to select stimuli for the treatment variable, brand prominence (prominent versus subtle), which was manipulated during the study. It was conducted in two stages. In stage 1, we conducted a focus group interview with 10 student players to select a few advergames. In stage 2, another 40 students were randomly selected and were called to a computer laboratory to play and rate the prominence of the games on a seven point bipolar scale $(1=$ "not at all prominently placed" to $7=$ "very prominently placed" $)$. Based on the mean ratings, 
prominent brand placement advergames (above 3.5) and subtle brand placement advergames (below 3.5) were selected for the study.

After pretest 1, pretest 2 was performed to select manipulated scenarios to induce gamers' involvement with the selected game by conducting a focus group interview with same 10 student players. The study decided to use scenarios to induce game-involvement as recommended by Bitner (1990). He stated that scenarios are role playing experiments that allow expensive or difficult manipulations to be more easily operationalized, provide control over other unmanageable variables, and enable compression of time by crisping events that might otherwise take more number of days or weeks. Scenario based method permits investigators to manipulate the independent variables of interest into several levels which is not possible in case of retrospective methods. Also, this method lessens the difficulties related with recall-based designs such as memory biases and consistency issues (Smith, Bolton, R.N., \& Wagner, 1999). Gameinvolvement scenarios were created through expert interviews with three professors working in the area of marketing from a large Indian University. These professors created six gameinvolvement scenarios ( 3 scenarios for high game-involvement and 3 scenarios for low gameinvolvement). Then, 30 student respondents were randomly selected to give their realism responses to these six scenarios by using a five point bipolar scale $(1=$ "very unreal scenario" to 5 = "very real scenario". Based on the realism scores $(>4)$, two scenarios were selected for the final study. In the selected high game-involvement scenario, subjects were instructed that their views on online games were very important as the game developers and game designers need their valuable suggestions on online games to improve game's quality before its launch in the market. Also, they were told that if the game developers find their suggestions really worth, they would be awarded a cash prize of Rs. 5000 with a commendation certificate from the company which would help them even in their job placements too. Also, they were communicated that if they would score high in the given game then they would have a favorable chance to win Rs.10000 cash in a lottery. In low game-involvement scenario no such statement about their views' importance or a chance to win Rs. 5000 or placement offer or any chance to win lottery was made in the low involvement condition.

\section{Participants, Method and Design}

As part of the final study, we asked 400 under-graduate management students from a large Indian University for their willingness to participate in a game playing experiment. 248 student gamers informed their willingness to participate in the experiment. Literature shows that $90 \%$ of teens are gamers (mediaedge:cia, 2005), which validates the use of student sample for the present study. These players were between the ages 17 and 22 years. All these 248 players were invited to a common computer laboratory for a game playing experiment. Then, these gamers were randomly allocated to any of the four experimental conditions. After the allocation of gamers to experimental conditions, they were asked to play the advergames on individual consoles for given time frames. After the completion of game play, participants in all the four conditions were presented a questionnaire depicting the manipulated scenarios, the manipulation check measures, measures for non-manipulated independent variable (game-involvement) and dependent measures. Half the gamers played prominent-placed advergames and the rest played subtle-placed games. Similarly, half the gamers read about high game-involvement inducing scenario, and rest read about a low game-involvement inducing scenario. 19 participants did not finish the game playing task on time, thus, all reported results refer to 229 student gamers.

\section{Independent Variables and Dependent Measures}

Brand prominence and game-involvement are the two independent manipulated variables and brand recall and brand attitude are the dependent variables used in the study. After the exposure 
to the advergames the respondents were asked to recall the brand names appeared in the game and write down the respective names. During the data coding process the individual recall score was calculated based on the number of brands each individual was able to recall out of the total exposed brands in the respective advergames. For example, if a participant listed only one advertised brand correctly out of 5 exposed ads during game play, it was coded as a correct response and was given a numerical value equal to 1 , as the numbers of correct responses ranged from 0-5. Brand attitude was measured by using a semantic differential scale with the bipolar adjective items (good/bad, like/dislike, favorable/unfavorable, and positive/negative), adapted from Muehling \& Laczniak (1988).

\section{Findings}

\section{Manipulation checks}

During the study, to examine the manipulation of brand prominence, respondents were asked to rate the brand prominence by using the same measure used in Pretest 1 . The results of one-way ANOVA showed a significant difference $(F(1,228)=61.754, p<0.05)$ between prominent brand placement advergames $(M=4.124)$ and subtle brand placement advergames $(M=2.952)$. The results of one-way ANOVA showed a significant difference $(F(1,228)=27.348, p<0.05)$ between high game-involvement $(M=5.989)$ and low game-involvement $(M=2.34)$ conditions. Further the examination of realism measures showed that all the gamers perceived that these scenarios were realistic $(M=5.22, p<0.001)$. These findings supported the fact that the manipulation of game-involvement through scenarios was successful.

Hypothesis testing. A 2 (brand placement: prominent or subtle) $\times 2$ (game-involvement: high or low) between-subject measures Multivariate Analysis of Variance (MANOVA) was performed with brand recall and brand attitude as the dependent measures. Results revealed a significant two-way interaction for brand prominence $\times$ game involvement on brand recall (Wilks $\Lambda=0.786$, $\mathrm{F}(2,228)=196.34, p<0.05)$. A detailed examination through pre-planned contrast tests showed that prominent brand placement (versus subtle brand placement) in low game-involvement condition was significant and resulted in high brand recall (Wilks $\Lambda=0.521, \mathrm{~F}(2,228)=69.41, p<$ 0.05, M Recall (Prominent Placement/High Involvement $=2.12), M$ Recall $\quad($ Prominent Placement /Low Involvement $=4.13)$ ). Furthermore, results showed that prominent brand placement (versus subtle brand placement) in high game-involvement condition was significant and resulted in more favorable brand attitude (Wilks $\Lambda=0.436, \mathrm{~F}(2,228)=78.32, p<0.05, \mathrm{M}$ Attitude (Prominent Placement//High Involvement = 3.98), $\mathrm{M}$ Attitude (Prominent Placement/Low Involvement $=2.23)$ ). Thus, hypotheses 1 and 2 are supported.

\section{Conclusion and Discussion}

Advertisers using brand placements in a number of media channels target consumers with a purpose that the advertised brands must get noticed by more number of customers eliciting their positive responses towards the in-game placed brands (Karrh, Brittain McKee, \& Pardun 2003). Here in this study we examined a research question that do brand prominence and gameinvolvement influence consumers' recall and attitude towards the brand embedded in the game, if it influences, then what are the conditions under which, this effect could be more effective, are explored in this study. Using LCM (Kahneman, 1973) and ELM (Cacioppo \& Petty, 1979), this study hypothesized the simultaneous effect of brand prominence and game involvement on gamers' memory and attitude. As projected by the proposed set of hypotheses, the results showed that advergames with prominent brand placements under low game involvement result in high recall but less favorable brand attitude than those with prominent brand placements under high game involvement condition. These findings supported the integrative theoretical perspective of LCM and ELM, that in case of prominent placed games, more spare capacity remains to process 
in-game brand information and when a gamer plays such a game under a low game involvement condition, it results in high recall but less favorable brand attitude than under high-involvement condition. The findings highlights that while inspecting gamers' recall and brand attitude, it is must to take into account the attention and elaboration aspects simultaneously, because here in this study we found that consumers' processing of advertised brand information is chiefly caused by attention element (brand prominence) and its further conditioned by elaboration element (game-involvement).

\section{Limitations and Scope for Future Research}

This study used only two levels of brand prominence and two levels of game-involvement. Effect of moderate levels of brand prominence and game-involvement on gamers' brand outcomes can be further investigated. Second limitation is that this study was conducted on Indian gamers, thus, these findings can be further confirmed on gamers from other countries, where the usage rate of online games is different from that in India. Another limitation of the study is that it tested the moderating effects of game involvement on gamers' memory and brand attitude, however, moderating effect of various other factors, such as game-product congruity and product involvement can be examined in future research.

\section{Managerial Implications}

Despite of a big hype about interactive media such as online games and the internet, very less empirical research has been conducted to investigate how advergame playing may influence brand placement effectiveness. This research is done to explore this issue in detail. This piece of work is the first attempt to show an integrative perspective of ELM and LCM in the context of online advergames. The examination of potential effects of brand prominence and gameinvolvement provides new insights into how these advergames may affect consumers' brand responses. Also, these results give vital insights for advertisers and game developers in terms of the design and evaluation of advergames. If advertisers want to develop advergames which can result in high recall then they must consider games embedded with prominent brand placements and low-involving in game-nature. However, to develop more favorable brand attitude, advergames with prominent brand placements and high involving in nature can be developed. Therefore, the advertising practitioners can design more effective advergames by taking into account some very important game-specific factors i.e. the brand prominence and the gameinvolvement. 


\section{References}

Alvy, L. M., \& Calvert, S. L. (2008). Food marketing on popular children's web sites: A content analysis. Journal of the American Dietetic Association, 108(4): 710-713.

Bitner, M. J. (1990). Evaluating service encounters: The effects of physical surroundings and employee responses. Journal of Marketing, 54(2): 69-82.

Business Wire. (2008. Exclusive PQ Media Research: Branded Entertainment Market Defies Slowing Economy, Expands $14.7 \%$ to $\$ 22.3$ Bil. in 2007. Available at: http://www.businesswire.com/news/home/20080212005817/en/Exclusive-PQ-MediaResearch-Branded-Entertainment-Market\#.VZzO0_mqqko (accessed March 13 2020).

Cacioppo, J. T., \& Petty, R. E. (1979). Effects of message repetition and position on cognitive response, recall and persuasion. Journal of Personality and Social Psychology, 37(1): 97-109.

Cauberghe, V., \& De Pelsmacker, P. (2010). Advergames: The impact of brand prominence and game repetition on brand responses. Journal of Advertising, 39(1): 5-18.

Chen, K. H., Shen, K. S., \& Ma, M. Y. (2012). The functional and usable appeal of Facebook SNS games. Internet Research, 22(4): 467-481.

Cicchirillo, V., \& Lin, J. (2011). Stop playing with your food. Journal of Advertising Research, 51(3): 484-498.

Dentsu Aegis Network. (2014). Carat predicts digital spend to reach more than 25\% of total advertising spend in 2016, fuelled by upsurge in mobile advertising spending in 2015. Available at: http://www.dentsuaegisnetwork.com/media/dentsu-aegis-network-news/2015/2015-0324 (accessed April 29 2020).

Dias, M., \& Agante, L. (2011). Can advergames boost children's healthier eating habits? A comparison between healthy and non-healthy food. Journal of Consumer Behaviour, 10(3): 152-160.

Emarketer. (2014). Mobile continues steal share of US adults daily time spent with media. Available at: http://www.emarketer.com/Article/Mobile-Continues-Steal-Share-of-US-Adults-DailyTime-Spent-with-Media/1010782 (accessed June 19 2020).

Faber, R. J., Lee, M., \& Nan, X. (2004). Advertising and the consumer information environment online. American Behavioral Scientist, 48(4): 447-466.

Folkvord, F. (2012). The effect of playing advergames promoting healthy or unhealthy foods on actual food intake among children. Appetite, 59(2): 625.

Folkvord, F., Anschutz, D. J., Wiers, R.W., \& Buijzen, M. (2015). The role of attentional bias in the effect of food advertising on actual food intake among children. Appetite, 84(1): 251-258.

Ghirvu, A. I. (2013). The aida model for advergames. The USV Annals of Economics and Public Administration, 13(1): 90-98.

Grigorovici, D. M., \& Constantin, C. D. (2004). Experiencing interactive advertising beyond rich media: impacts of ad type and presence on brand effectiveness in 3D gaming immersive virtual environments. Journal of Interactive Advertising, 5(1): 31-53.

Gupta, P. B., \& Lord, K. R. (1998). Product placement in movies: The effect of prominence and mode on audience recall. Journal of Current Issues \& Research in Advertising, 20(1): 47-59.

Hofmeister-Tóth, Á., \& Nagy, P. (2011). The content analysis of advergames in Hungary. Qualitative Market Research: An International Journal, 14(3): 289-303. 
Huang, J. H., \& Yang, T. K. (2012). The effectiveness of in-game advertising: The impacts of ad type and game/ad relevance. International Journal of Electronic Business Management, 10(1): 61-72.

Ipe, M. (2008). Advergaming and ingame advertising. Hyderabad: Icfai University Press.

Kahneman, D. (1973). Attention and effort. Englewood Cliffs: Prentice Hall, New Jersey, NJ.

Karrh, J. A., Brittain McKee, K. and Pardun, C. J. (2003). Practitioners' evolving views on product placement effectiveness. Journal of Advertising Research, 43(2): 138-149.

Krugman, H.E. (1983). Television program interest and commercial interruption: Are commercials on interesting programs less effective? Journal of Advertising Research, 23(1): 21-23.

Lang, A. (2000). The limited capacity model of mediated message processing. Journal of Communication, 50(1): 46-70.

Laverie, D. A., \& Arnett, D. B. (2000). Factors affecting fan attendance: The influence of identity salience and satisfaction. Journal of Leisure Research. 32(2): 25-46.

Lee, M., \& Faber, R. J. (2007). Effects of product placement in on-line games on brand memory: A perspective of the limited-capacity model of attention. Journal of Advertising, 36(4): 75-90.

Lee, M., Choi, Y., Quilliam, E. T., \& Cole, R. T. (2009). Playing with food: Content analysis of food advergames. Journal of Consumer Affairs, 43(1): 129-154.

Livemint. (2015). GroupM says ad spends to grow by $12.6 \%$ in 2015. Available at: http://www.livemint.com/Consumer/nAhthSk6371gEVIQiZ929J/Indian-advertisingexpenditure-to-touch-Rs49000-crore-in-20.html (accessed February 15 2020).

Lynch, J. G., \& Srull, T. K. (1982). Memory and attentional factors in consumer choice: Concepts and research methods. Journal of Consumer Research, 9(1): 18-37.

McClung, G. W., Park, W. W., \& Sauer, W. J. (1985). Viewer processing of commercial messages: context and involvement. Advances in Consumer Research, 12(1): 351-355.

Mediaedge:cia. (2005). Playing with brands. Available at: http://www.meeglobal. com/output/Page1463.asp (accessed October 15 2019).

Moore, E. S. (2006). It's child's play: Advergaming and the online marketing of food to children. Menlo Park: Kaiser Family Foundation, CA.

Muehling, D. D., \& Laczniak, R. N. (1988). Advertising's immediate and delayed influence on brand attitudes: Considerations across message-involvement levels. Journal of Advertising, 17(4): 23-34.

Nairn, A., \& Hang, H. (2012). Advergames: It's not child's play. A review of research. Family and Parenting Institute.

Paek, H. J., Quillium, E. T., Kim, S., Weatherspoon, L. J., Rifon, N. J., \& Lee, M. (2014). Characteristics of food advergames that reach children and the nutrient quality of the foods they advertise. Internet Research, 24(1): 63-81.

Petty, R. E., \& Cacioppo, J. T. (1986). The elaboration likelihood model of persuasion. Advances in Experimental Social Psychology, 19: 123-205.

Rothschild, M. L. (1984). Perspectives on involvement: Current problems and future directions. Advances in consumer research, 11(1):216-217. 
Smith, A.K. Bolton, R.N., \& Wagner, J. (1999). A model of customer satisfaction with service encounters involving failure and recovery. Journal of Marketing Research, 36(3):356-372.

Statista (2015). Digital advertising spending in India from 2012 to 2018 (in billion U.S. dollars). Available at: http://www.statista.com/statistics/237962/online-advertising-spending-inindia/ (accessed June 25 2020).

Tavassoli, N. T., Shultz, C.J, \& Fitzsimons, G. J. (1995). Program involvement: Are moderate levels best for ad memory and attitude toward the ad? Journal of Advertising Research, 35(5): 6172 .

Van Reijmersdal, E. (2009). Brand placement prominence: good for memory! Bad for attitudes? Journal of Advertising Research. 49(2): 151-153.

Van Reijmersdal, E. A., Rozendaal, E., \& Buijzen, M. (2012). Effects of prominence, involvement, and persuasion knowledge on children's cognitive and affective responses to advergames. Journal of Interactive Marketing, 26(1): 33-42.

Vashisht, D. (2015), “Effect of advergames on customers' brand memory, persuasive intent and brand attitude: an empirical study in Indian context", available at: http://ir.inflibnet.ac.in:8080/jspui/handle/10603/73725 (accessed on August 7 2020).

Vashisht, D. \& Mohan, S. (2018). Game-speed influence and brand attitude: mediating role of thought favorability in in-game advertising. Arts and the Market, 8(1): 99-112.

Yang, M., \& Roskos-Ewoldsen, D. R. (2007.) The effectiveness of brand placements in the movies: Levels of placements, explicit and implicit memory, and brand-choice behavior. Journal of Communication, 57(3): 469-489.

Youn, S., \& Lee, M. (2012). In-game advertising and advergames: A review of the past decade's research. Advertising Theory, 388-401. 